\title{
Post Graduate Curriculum and Skill of Teacher
}

\author{
Sunil Kumar ${ }^{1}$ - Arunima Verma ${ }^{1}$
}

Published online: 11 October 2017

(C) Association of Surgeons of India 2017

The curriculum in any course is more than just a syllabus and embraces all the learning opportunities both formal and informal. The concept of curriculum has been widened to include the learning outcomes, teaching and learning methods, educational strategies, the context of learning, the learning environment and assessment procedures. The curriculum development is a systematic process that involves a series of planned steps. The curriculum is seen as expression of intentions, mechanism and context of education programme that requires input from all stakeholders.

A distinction should be made between planned, delivered and learned curriculums. The planned curriculum is documented and agreed by curriculum planners and teachers and embodies their intentions and aspirations - curriculum on paper. The actual or delivered curriculum is the reality of student experience and what is delivered or happens in practice - curriculum in action. The learned curriculum represents the students' knowledge, skills and attitudes that result from learning experience. A mismatch between planned and delivered curriculum may be due to teachers' lack of familiarity, skill or acceptance of the curriculum.

UK General Medical Council in Good Medical Practice mentioned 'If you have responsibilities for teaching, you must develop the skills, attitude and practices of a competent teacher'.

Surgical training needs to change in order to respond to advances in medicine, alterations in health care delivery system, patients' expectation and new learning technologies. Visible pressure from various stakeholders is there for quality

Sunil Kumar

drsunil.jsr@gmail.com

1 Department of Surgery, Tata Main Hospital, Jamshedpur, India assurance, accountability, performance measures and standard in medical education.

There are three elements in surgical education - the curriculum, the trainee and teacher. The teacher is the key element in the creation of condition in which learning occurs. Teaching and training may be seen as common sense but past experience shows that when it comes to putting it into practice, most of the teachers are found wanting. An effective teacher requires a combination of technical competence, appropriate approach to teaching and professionalism.Technical competencies would consist of preparing and giving lecture, teaching clinical and surgical skill, facilitating and managing learning and assessing trainees. Approach to teaching would consist of understanding the principles of education, appropriate attitude, ethical understanding and best evidence-based education. Professionalism would comprise the role of the teacher within health service and personal development with regard to teaching.

Good trainers are not only the transmitters of information and skill but facilitators of students' learning.

Teaching and training is a professional activity and good teaching is best delivered when there is understanding of the underlying process. The role of the teacher has to change where students are empowered to take responsibility of their own learning and that is why there is a move from teachercentred learning to student-centred learning. As Winston Churchill said, 'I am always ready to learn although I do not like being taught'. Student-centred learning is more motivating for students. In student-centred learning, the teacher still has an important role to play.

Problem-based learning is a good educational strategy in medical course where the starting point of learning is a clinical problem. Students find the process enjoyable and motivating. Problem-based learning also addresses learning outcomes such as teamwork and problem-solving. 
Work-based learning is a key strategy in post graduate education where trainees learn on the job while doing the job. The core condition for WBL is a supported participation. The work environment has powerful learning potential and can meet the criteria for effective and efficient learning.

Learning should be based on FAIR principle:

1. F-Feedback. Giving feedback to students as they progress to the mastery of the expected learning outcome

2. A-Activities. To engage the trainees in active learning as opposed to passive learning

3. I-Individualisation. Relate the learning to the needs of individual.

4. $\mathrm{R}-$ Relevance. To make learning relevant to trainees in terms of their career objectives

There is an important trend on greater emphasis on outcomebased education (OBE) which means teachers have to identify and ensure the learning outcomes expected to their trainees. The concept of OBE was promoted by Spady (1994). He defined OBE as 'a way of designing, developing, delivering and documenting instruction in terms of its intended goal and outcomes'. There are many advantages of OBE like it highlights the competencies to be achieved, it is necessary given the rapid advances in surgical education, it emphasises accountability and transparency in medical education, it points students in the right direction and it ensures that assessment is more valid. SAT (summative assessment test) is an assessment of trainees at the end of their training period and if performance of trainee is not satisfactory, then no intervention is possible. That is why there is a move towards FAT (formative assessment test) where there is periodical assessment of trainee during training period and if required, some form of intervention can be done to improve trainee performance so as to ensure that they are able to achieve their pre-determined learning objective.

Trainee $\rightarrow$ Contents $\rightarrow$ Learning methods and strategy $\rightarrow$ Learning environment $\rightarrow$ Formative assessment $\rightarrow$ Learning outcome

So, the following should be the features of a good teacher:

1. Plans the clinical teaching with clearly defined learning outcome

2. Appears to be enthusiastic with a positive attitude

3. Serves as positive role model demonstrating good relationship with patients

4. Helpful and available to patients

5. Encourages trainees' active participation

6. Patient-oriented with problem-solving

7. Observes students examining patients and performing procedures and gives feedback

8. Provides students the opportunity to practice their skill
9. Individualises the teaching to the stage of training

To have objectivity, learning outcomes are structured round a number of domains usually not more than 12 . Each domain represents a category of learning outcome. Several learning outcome frameworks have been described. The one which is very commonly used is the Dundee three circle outcome model.

Inner circle. It represents the technical skill (performance of task) - doing the right thing. It includes seven domains:

1. Clinical skill

2. Practical procedures

3. Patient investigation

4. Patient management

5. Health promotion and disease prevention

6. Communication

7. Information handling skill

Middle circle (approach to task). It represents the way the task is approached in inner circle - doing the right thing.

8. Understanding of social, basic and clinical services

9. Appropriate attitudes and ethical understanding

10. Decision-making skill and clinical judgement

Outer circle. It represents the personal attributes of the individual — the right person doing it (professionalism)

11. Role of trainee

12. Continuous professional and personal development

\section{Dundee Three Circle Learning Outcome Model}

The good teacher and trainee have to be familiar with learning outcome framework as good teacher is supposed to be having all the competencies described and trainees are supposed to work professionally with guidance from the teacher during their training period by utilising various educational strategies so as to achieve all domain competencies. It is only through the total synergy between good curriculum, trainee and teacher with the help from all stakeholders and excellent learning environment that post graduate trainee can turn into a competent and humane surgeon ready to move on in life. 